\title{
QUESTÕES DE ROMANCE: NOTAS SOBRE ANTONIO CANDIDO E A CRÍTICA BRASILEIRA
}

http://dx.doi.org/10.11606/issn.2237-1184.v0i30p64-81

Edu Teruki Otsuka ${ }^{\mathrm{I}}$

\section{RESUMO}

Este artigo focaliza alguns artigos de Antonio Candido sobre o romance, publicados nos anos 1940 e 1950, e examina algumas discussões sobre o desenvolvimento do romance no Brasil no período de redação de Formação da literatura brasileira, buscando situar as ideias de Candido em seu contexto crítico particular.

\section{ABSTRACT}

This paper focuses on Antonio Candido's essays on the novel, from the 1940s and 1950s, and reviews some debates concerning the development of the novel form in Brazil at the time he wrote Formação da literatura brasileira, in order to locate Candido's ideas in their specific critical context.

\section{PALAVRAS-CHAVE:}

Antonio Candido; romance e sociedade; crítica literária brasileira; José de Alencar; Machado de Assis.

\section{KEYWORDS}

Antonio Candido; novel and society; Brazilian literary criticism; José de Alencar; Machado de Assis.

I Universidade de São Paulo, São Paulo, São Paulo, Brasil. 
1 o investigar o desenvolvimento, as realizações e os problemas formais do romance em suas condições determinadas de produção, a teoria e a crítica frequentemente foram conduzidas à indagação acerca do rumo histórico da sociedade, através da discussão de questões literárias. Pensar o romance em termos exigentes era também perguntar-se sobre as possibilidades e os limites da modernidade capitalista e, nas áreas periféricas do sistema produtor de mercadorias, o romance, suprema mercadoria cultural do século XIX, foi um objeto de desejo que sinalizava igualmente uma aspiração a certo tipo de organização social. No Brasil, a historiografia literária e a crítica sobre o romance não raro tiveram de enfrentar questões que inevitavelmente levavam a pensar sobre o que era percebido como o grau de desenvolvimento da sociedade enquanto condição de possibilidade do romance, dada a imbricação entre essa forma literária e a matéria social especificamente burguesa nela elaborada. Mesmo quando pouco equipada em termos teóricos, a crítica sobre o romance não deixou de apresentar, às vezes conscientemente, às vezes como sintoma, elementos para uma reflexão acerca da sociedade brasileira.

\section{As faces da realidade}

Tendo em vista o potencial alcance da investigação crítico-teórica sobre o romance e sua abertura para a meditação acerca da sociedade e suas opções históricas, não admira que a tentação de arriscar um estudo desse tipo tenha, desde cedo, rondado os projetos intelectuais de Antonio Candido e tenha sido formulado como um desígnio discernível no início dos anos 1950, retomando o intuito de discutir a trajetória da forma romance - sua emergência, seu desenvolvimento e seu destino - que já se manifestava desde os anos precedentes. Em 1951, ele declara ter em preparação um livro inteiramente voltado ao romance, combinando uma perspectiva teórica aos estudos específicos que vinha produzindo em seus rodapés e artigos.

Antonio Candido o faz justamente ao dar por terminada a primeira redação de Formação da literatura brasileira, livro então anunciado como recém-concluído e pronto para ir ao prelo. No entanto, como se sabe, Formação ainda permaneceria alguns anos na gaveta até passar por uma revisão entre 1955 e 1957, após ser submetido à leitura de Décio de Almeida Prado e Sérgio Buarque de Holanda, como Candido declara no Prefácio (cf. CANDIDO, 1993b, p. 10). Só então foi entregue ao editor, que por sua vez postergou a publicação, a qual se concretizou em 1959 por insistência do 
autor, que julgava importante ter uma obra mais substancial na área dos Estudos Literários, pois, naquele momento, tendo deixado a função de Assistente de Sociologia, Antonio Candido intencionava voltar à Universidade de São Paulo para assumir o curso de Teoria Literária e Literatura Comparada, depois de dois anos ensinando Literatura Brasileira na Faculdade de Assis, no interior do Estado (cf. SERNA, 2012).

Para o caso brasileiro, o trabalho de Antonio Candido certamente se apoiou na tradição de estudos sobre o tema que vinha se definindo a partir dos críticos românticos, passando por Sílvio Romero e José Veríssimo, e chegando a Prudente de Moraes Neto e Sérgio Buarque de Holanda, Lúcia Miguel Pereira e Augusto Meyer (para citar apenas alguns nomes centrais). Sua obra, especialmente Formação da literatura brasileira, retomava essa tradição, aproveitando seus achados ao mesmo tempo em que elaborava um juízo refletido das perspectivas críticas, sociais e políticas nela acumulada. Assim, recolhia e desdobrava, no plano da crítica, os resultados daquilo que a própria Formação descrevia como processo de adensamento cultural e constituição de um campo de problemas próprio, elaborado na articulação interna do sistema literário em maturação. ${ }^{1}$

Concluído o estudo amplo sobre o período formativo da literatura brasileira, Antonio Candido imaginou uma obra dedicada ao romance, com ênfase em autores estrangeiros. A informação sobre esse livro planejado, mas nunca publicado como tal, consta em artigo de um jornalista da Folha da Manhã que o entrevistou em 1951, e, embora o livro não tenha chegado a existir - pelo menos não do modo como foi então pensado -, é possível reconhecer ou inferir parte do projeto que ali se delineava. Segundo a reportagem, o livro se chamaria As faces da realidade e seria composto de sete ensaios, assim indicados: 1. "A arte do romance como forma e problema"; 2. "Stendhal e a retidão literária"; 3. "Anatole France ou a vitalidade da dúvida"; 4. "Eça de Queirós entre o campo e a cidade"; 5. "Silone, virtudes e defeitos da pureza"; 6. "Graciliano Ramos e o gênio dos lugares"; 7. "As faces da realidade" (cf. MIRANDA, 1951; NOTÍCIA, 1951).

Procurando depreender algo do teor dos ensaios a partir dos títulos, pode-se imaginar que o primeiro e o último textos iriam emoldurar o conjunto com estudos de caráter mais geral. Indicações de uma discussão teórica e histórica da forma romance já haviam aparecido em artigos de rodapé publicados antes, entre os quais se destacam "O romance e o $D$. Juan" e "Esclarecendo", ambos de 1944, nos quais Antonio Candido discute a constituição do romance, associada à progressiva expansão da experiência burguesa na Europa ocidental, e especula sobre o destino da forma, atrelado ao futuro da organização social presente e às perspectivas de sua transformação (cf. CANDIDO, 1944b, 1944a).

\footnotetext{
${ }^{1}$ Estudos fundamentais sobre o tema são os de Roberto Schwarz $(1987,1999)$ e Paulo Arantes $(1992,1997)$, em cujas ideias este artigo se apoia largamente.
} 
No tocante ao corpo da obra planejada, alguns dos títulos remetem a textos anteriormente publicados por Antonio Candido, talvez implicando um intuito de refundir ou desenvolver textos prévios. Sem pretender especular demais sobre um livro inexistente, tentemos apenas uma caracterização sumária. Em 1943 Antonio Candido havia produzido dois artigos sobre Stendhal, publicados na Folha da Manhã, os quais seriam depois refundidos sob o título "Uma dimensão entre outras" em $O$ observador literário, de 1959 (CANDIDO, 1992a). Neles, Candido aponta em Stendhal o equilíbrio de análise psicológica e investigação social, aborda o tema do arrivismo e comenta a descrição da batalha de Waterloo na Cartuxa de Parma, para discutir o modo como o romancista transfigura o acontecimento histórico por meio da percepção subjetiva do personagem. ${ }^{2}$ Quanto a Anatole France, embora Candido não tenha, ao que parece, escrito extensamente sobre ele (cf. DANTAS, 2002), a relação entre literatura e história parece ser o aspecto motivador de seu interesse pelo romance Os deuses têm sede, considerado uma "verdadeira obra prima de romance histórico-político" (CANDIDO, 1946b), capaz de ensinar mais sobre a Revolução Francesa do que um tratado porque convida a olhar, "não de fora para dentro (dos acontecimentos para os homens), mas de dentro para fora, dos homens para os acontecimentos" (CANDIDO, 1946a).

O estudo sobre Eça de Queirós, com esse mesmo título, havia sido publicado em livro coletivo organizado por Lúcia Miguel Pereira e Câmara Reys em 1945 e seria depois republicado em Tese e Antítese, de 1964 (CANDIDO, 1971). Ali Candido discute a mudança de perspectiva ao longo da produção de Eça, do olhar citadino aderente ao progresso, que critica o imobilismo da província, à denúncia da superficialidade da civilização burguesa, por meio da valorização da vida rural tradicional. Já os romances de Ignazio Silone haviam sido objeto de comentário extenso de Candido em uma série de três artigos mais um apêndice, publicada em 1946 no Diário de S. Paulo e nunca recolhida em livro. Comentando a questão do romance político, Candido argumenta que Silone, "enquanto artista e revolucionário", procura "chegar ao conhecimento das molas que impelem a política", ultrapassando a forma partidária "para ficar com o que existe de mais geral no impulso revolucionário", que para o crítico seria "coextensivo com o humano" (CANDIDO, 1946b). Por fim, o ensaio previsto sobre Graciliano Ramos faz pensar no conjunto de cinco artigos publicados no Diário de S. Paulo em 1945 e que o crítico refundiria em Ficção e confissão, publicado como opúsculo em 1956 (CANDIDO, 1992b). Também em Graciliano, o interesse de Candido parece voltar-se para a

${ }^{2} \mathrm{O}$ interesse de Antonio Candido pela representação literária de eventos históricos perdurou ao longo de sua vida, e a descrição de Stendhal seria ainda uma vez revisitada em "Batalhas" (cf. CANDIDO, 2010). 
capacidade do romancista de ultrapassar o dado documental, referente ao problema geográfico e social, por meio da invenção propriamente literária.

O livro anunciado em 1951 talvez tomasse como eixo unificador a discussão das possibilidades do romance enquanto elaboração artística da experiência histórica. Estão lá questões como a expansão da experiência burguesa, suas promessas e desilusões; o parâmetro de modernidade que incide sobre as áreas periféricas, suscitando o confronto crítico com o atraso; as possibilidades de luta política em condições materiais adversas; a permanência dos problemas sociais que pedem resolução. Além disso, ao comentar alguns romances políticos da época - entre os quais Trevas ao meio dia, também conhecido como $O$ zero e o infinito, de Arthur Koestler Candido destaca a importância da tarefa a que eles se propunham: "incorporar ao domínio da arte, libertando-os da reportagem e da polêmica, certos grandes acontecimentos do nosso tempo" (CANDIDO, 1946b; v. também 1946a).

Aquele já não era o momento eufórico das perspectivas de transformação segundo a orientação socialista do crítico; o que se anunciava era antes um quadro em que se impunha a necessidade de refletir sobre o sentido da revolução social e seus descaminhos. De 1950 /1951, por sinal, é o retrato de Antonio Candido pintado por Arnaldo Pedroso d'Horta - retrato marcado por uma melancolia que habitualmente não se mostrava no semblante de Antonio Candido, mas que, de acordo com a leitura de Ana Luisa Escorel, a sensibilidade de Arnaldo Pedroso d'Horta soube captar naquele momento, parecendo "prefigur[ar] a vitória de uma ordem política e social iníqua, muito distante das expectativas de mocidade tanto do modelo quanto de seu pintor" (2016, p. 14). ${ }^{3}$

\section{A crítica brasileira e o romance}

Com relação à crítica brasileira imediatamente anterior ou contemporânea da redação de Formação da literatura brasileira, cabe lembrar, inicialmente, o trabalho de Prudente de Moraes Neto, O romance brasileiro, publicado em 1939. Trata-se de um dos primeiros e mais significativos estudos de conjunto do romance brasileiro, escrito depois do surgimento do romance de 1930, que parecia alçar a produção literária brasileira a um novo patamar qualitativo, estabelecendo uma plataforma a partir da qual se tornava possível à crítica rever o passado sem condescendência. Referência reconhecida por Antonio Candido como inspiradora de ideias para a elaboração do capítulo sobre o aparecimento do romance na Formação da literatura brasileira, o estudo de Prudente apresenta

\footnotetext{
${ }^{3}$ A lembrança da evocação do retrato por A. L. Escorel se deve a Paulo Arantes, em palestra proferida no "Colóquio Bento Prado Jr.: Aventuras da Filosofia Brasileira", na FFLCH-USP, em 5 de junho de 2017.
} 
observações sugestivas sobre o problema das condições de possibilidade do romance no Brasil.

Após constatar o surgimento relativamente tardio do romance no país, o crítico destaca entre as causas desse atraso "o meio social desfavorável", pois, a seu ver, "a severa concepção patriarcal da família que serviu de arcabouço a toda a construção da sociedade colonial, não só era uma evidente limitação da própria matéria romanceável, como um impedimento à formação do ambiente necessário à literatura novelesca" (MORAES NeTO, 2004, p. 204). Além de questões como a pouca irradiação da instrução, a exclusão das mulheres da vida intelectual, o direcionamento do interesse dos homens às questões práticas, a preferência dada à poesia pelos letrados e as dificuldades materiais de publicação, Prudente assinala o que entende como deficiência da própria matéria: "A vida simples e rude era pouco densa, muito desigual" (2004, p. 204). Note-se que essa imagem que sugere a falta de densidade do meio social e da vida cultural no Brasil, como veremos, retornará em diferentes formulações de outros críticos, incluindo o próprio Antonio Candido.

Para Prudente, o romance é produto da civilização (infere-se, especificamente moderna) e alimenta-se de matéria condicionada pelo meio social, funcionando como "índice de determinado grau de cultura e desenvolvimento das relações sociais" e, embora evite afirmar um vínculo direto entre romance e burguesia, o crítico reconhece que "o romance depende e é função da intensidade da vida social" (Idem, p. 205). Desse modo, suas observações sugerem que o desenvolvimento incipiente do romance brasileiro em seus inícios se relacionaria com a suposta falta de complexidade da matéria social à época.

Ao final de seu estudo, Prudente de Moraes Neto sugere correlações entre as sucessivas fases do romance e as transformações na sociedade. A seu ver, entre 1840 e 1870, o romance brasileiro não alcança "questões universais", limitando-se a tratar despretensiosamente da modesta vida local, e o pouco apuro das primeiras produções de ficção em prosa refletiria o meio social e literário daquela fase. No período posterior a 1880, em que teve lugar a Abolição e a República, juntamente com o "aumento da densidade da vida" (p. 232), Prudente constata transformações na sociedade e na literatura, mas as encara como continuidade dos naturalistas em relação aos românticos, uma "diferença de grau e de modo, não de natureza" (p. 233). Por fim, no começo do século XX, com a urbanização, o início da industrialização e o desenvolvimento econômico, o crítico assinala "o fim da transição do estado colonial para a verdadeira independência" (p. 233). Os escritores poderiam então trabalhar com material mais rico e, nas novas condições, que eram as do presente do autor, o romance brasileiro começaria a apresentar os requisitos que até então lhe faltavam (cf. 2004, p. 234). 
Como se vê, para Prudente de Moraes Neto a linha de evolução do romance brasileiro acompanharia certo desenvolvimento da sociedade, compreendido segundo a perspectiva de superação da condição colonial e de consolidação da independência nacional. Escrevendo no final dos anos 1930, Prudente constata naquele momento de transformações recentes os sinais que pareciam encaminhar o país rumo ao desejado estabelecimento de uma nação moderna.

Uma dificuldade, que permanecerá na crítica do período, é a de explicar o surgimento da obra madura de Machado de Assis, por muitos reconhecida como dotada de qualidade superior, especialmente a partir dos estudos surgidos por volta de 1939, quando se comemorou o centenário do escritor. Para Prudente, o principal fator explicativo seria a autoconsciência das próprias limitações: "foi o senso das proporções, a voluntária aceitação dos seus limites, que permitiu uma obra superior como a de Machado de Assis, que trabalhou sobre si mesmo e não voltou os olhos para fora senão para se orientar pela vida que via e procurar compreendê-la" (p. 233). Por ora, notemos apenas que, em Formação da literatura brasileira, Antonio Candido chegaria a sugerir algo semelhante ao tratar de Manuel Antônio de Almeida, que conseguiu apresentar uma "visão direta da sociedade" sem deixar-se impregnar pela retórica exagerada ou pelo apego ao sensacional; assim, conclui Candido, devido ao "senso dos limites e possibilidades da sua arte, [Manuel Antônio] pressagiou entre nós o fenômeno de consciência literária que foi Machado de Assis" (CANDIDO, 1993b, p. 199).

Em 1950, apareceu Prosa de ficção (de 1870 a 1920), estudo fundamental de Lúcia Miguel Pereira, cujo trabalho crítico Antonio Candido acompanhava com atenção. O livro havia sido originalmente concebido como um dos volumes de uma História da Literatura Brasileira dirigida por Álvaro Lins, a qual deveria ser escrita coletivamente por alguns dos principais críticos literários em atividade no período, mas, dado o malogro do projeto, Prosa de ficção fez carreira independente, firmando-se como obra de referência indispensável, mesmo tendo marcos temporais delimitados por um plano que lhe é externo.

Já no pórtico do estudo, Lúcia Miguel Pereira postula a necessidade, para o estudo da literatura brasileira, de articular o ângulo estético ao histórico, de modo a combinar a avaliação crítica sobre a realização artística das obras e a investigação das relações entre literatura e vida, sendo a perspectiva histórica especialmente importante porque as obras estudadas - em particular a prosa brasileira do século XIX - "representam sobretudo sintomas da evolução espiritual e social de um povo" (PEREIRA, 1957, p.14).

Tratando do romance como forma, Lúcia não hesita em articular seu aparecimento à ascensão da burguesia, primeiramente na Inglaterra setecentista e em seguida na França pós-revolucionária. Para ela, o 
romance se nutre diretamente da "vida de relação" - isto é, das relações intersubjetivas que se estabelecem em um quadro cultural e social determinado - e, por esse motivo, não poderia alcançar realização artística plena "numa sociedade sem estratificações profundas, de fraca densidade espiritual" (1957, p. 15, grifo meu). Após observar que o romance lida com as questões fundamentais da vida, não de maneira abstrata, e sim "tal como se revela[m] através de determinado grupo humano", Lúcia nota igualmente a importância das exigências postas pelos materiais que o romance elabora, de modo que a liberdade criadora do escritor é limitada pelas normas sociais: "Quando [a sociedade] não possui fisionomia própria, quando tateia à procura de si mesma, precária se torna a tarefa do romancista" (Idem, p.16). Em outras palavras, para ela uma sociedade imatura não poderia fornecer matéria adequada para a produção de um romance dotado de maior penetração social e psicológica.

$\mathrm{Na}$ compreensão da crítica, tratava-se de um déficit de realismo, paradoxalmente manifestado numa literatura aderente à realidade e pouco imaginativa, mas apegada ao real apenas em termos sentimentais, faltando-lhe a postura analítica e adulta que caracterizaria o realismo sério no sentido rigoroso: "A atitude serena e distante de Flaubert seria entre nós tão difícil - para não dizer impossível - quanto os puros sonhos de Villiers de L'Isle Adam" (p. 22). Assim, para ela, como tendência predominante, os escritores brasileiros "nem chegam a ver o mundo exterior tal qual é, nem dele se libertam" (p. 23), constituindo exceções a invenção imaginativa de Alencar e o pendor analítico de Machado. Embora pouco desenvolvida, essa observação de Lúcia é cheia de consequências para a compreensão das dificuldades de realização do romance brasileiro, particularmente no século XIX - e encontraremos uma formulação convergente no trabalho de Antonio Candido.

Para Lúcia Miguel Pereira, a publicação de Memórias póstumas de Brás Cubas seria o desfecho culminante da busca longamente intentada pela independência literária, a qual indicaria um "estado de maturidade intelectual e social que permite a liberdade de concepção e expressão". Apoiando-se nas ideias do próprio escritor, Lúcia observa que, entre todos, Machado possuiu o "sentimento íntimo de seu tempo e do seu país" e por isso "pôde [...] ser universal sem deixar de ser brasileiro" (p. 54). Por fim, cabe lembrar de que modo a crítica compreendia a relação entre o surgimento da obra superior de Machado de Assis e o desenvolvimento da sociedade brasileira:

Descontada a parte do coeficiente pessoal - sem dúvida a mais importante - a obra de Machado de Assis revela que já possuíamos, no fim do Segundo Reinado, um organismo social melhor definido do que faria supor a confusão reinante nos domínios literários entre o indivíduo e o meio físico ou o clã a que pertencia. $\mathrm{O}$ equilíbrio entre as suas personagens e o 
ambiente em que viviam denota, ao lado dos dons admiráveis do romancista, a existência de um estado cultural permitindo uma mais nítida diferenciação. (p. 55)

A sugestão de Lúcia Miguel Pereira, que tentava articular o surgimento da obra madura de Machado de Assis ao desenvolvimento do espírito crítico na vida cultural e talvez do próprio meio social, seria em parte contestada por Sérgio Buarque de Holanda. No artigo “Em volta do círculo mágico", de abril de 1950, ele observa que, no século XIX, o romance deitava raízes no solo em que surgiu e se estabeleceu como gênero literário independente, "o solo da sociedade burguesa e capitalista, conforme se constituíra em determinados países da Europa ocidental". A seu ver, o contraste e o conflito entre as tradições arraigadas e os novos valores burgueses é que forneceriam a matéria adequada ao romance. Isso o leva a discutir a situação do romance nas Américas, onde os escritores recebiam modelos já prontos, e "os gestos copiados a longa distância, no espaço e um pouco no tempo, não assumiam [...] o cunho natural e inevitável que deviam ter tido no cenário de origem"; de fato, tratava-se de "um mundo periférico: o verdadeiro centro ficava em Paris ou em Londres" (HOLANDA, 1996, p. 190). Ainda segundo Sérgio Buarque, no Novo Mundo, "onde tudo era praticamente informe", as instituições sociais proporcionavam ao romancista de costumes apenas uma "matéria tênue e instável", exigindo dele um esforço suplementar de preparação do material a ser elaborado (Idem, p. 191).

Diante das dificuldades que se impunham no mundo periférico, a tendência mais constante dos escritores brasileiros teria sido a de "apeg[ar]-se a expedientes que lhes serviam antes para escamotear as dificuldades do que para enfrentá-las com soberana decisão" (HOLANDA, 1996, p. 191). A seu ver, a supervalorização da cor local, tratada como elemento pitoresco, teria sido um desses subterfúgios. Por isso, acompanhando o argumento de Lúcia Miguel Pereira, Sérgio Buarque valoriza Machado de Assis por ter mostrado ser possível "criar-se uma arte brasileira de importância superior, sem recorrer ao brasileirismo de fachada, que em muitos casos não passa de disfarce para insuficiências íntimas"; em Machado, "a consciência de nacionalidade era total e não precisava, para impor-se, de elementos decorativos" (Idem, p. 193). No entanto, Sérgio Buarque questiona a validade da sugestão de Lúcia segundo a qual a maturidade artística de Machado corresponderia ao amadurecimento social que se teria alcançado no Segundo Reinado, e considera que o escritor não espelhou, mas se sobressaiu das condições de seu tempo em seu país, passando a constituir um caso à parte nas Letras brasileiras (p. 193-4). ${ }^{4}$

\footnotetext{
${ }^{4}$ Apenas como curiosidade, note-se que Sérgio Buarque retoma o assunto ao discutir o argumento de outro crítico que, para contestar as observações de Lúcia Miguel Pereira sobre as condições de
} 
Em outro artigo, "Situação do romance", de janeiro de 1951, Sérgio Buarque volta a discutir o problema da correlação entre a obra de Machado e o desenvolvimento social. Ele concorda com Lúcia Miguel Pereira na observação de que o romance, como forma, exige certo grau de maturação e complexidade da vida cultural e social, observando que no Brasil houve um prolongamento da atitude romântica, decorrente da "insuficiência de elementos romanceáveis". E, mais uma vez contestando a correspondência insinuada por Lúcia entre a maturidade de Machado de Assis e o amadurecimento da sociedade, Sérgio Buarque afirma que "a arte de Machado [...] formou-se a despeito das situações adversas que encontrou e retratou", pois considera que, apesar do relativo desenvolvimento verificado por volta de 1880, a sociedade brasileira "não deixou [...] de se conservar largamente aluvial, sem contornos definidos e sem a densidade necessária para alimentar, salvo casos excepcionais, uma arte social no sentido em que foi uma arte social o romance burguês europeu do século XIX" (p. 330, grifo meu).

Por fim, e para indicar a persistência do problema na consciência crítica brasileira, cabe lembrar um artigo de Augusto Meyer sobre José de Alencar. Nele, Meyer retoma termos de Raízes do Brasil, de Sérgio Buarque, para expressar a percepção de um desajuste, na obra de Alencar, entre o brilho verbal e a rarefação da matéria, ligada ao que denomina "vazio brasileiro, [...] tenuidade da nossa consciência nacional, sem lastro de tradições sedimentadas, capaz de alimentar a obra literária prescindindo do arrimo de influências peregrinas" (MEYER, 1964, p. 155). A seu ver, trata-se de uma "vacuidade inevitável, que é nossa também, é coletiva e não só do autor" (p. 156), "provocando entre os filhos de uma terra virgem, onde tudo é ainda conjetural, problemático e conjugado no futuro, uma crise de crescimento, uma exacerbação da vontade de afirmar-se" (p. 157). Assim, para Meyer, o instinto de nacionalidade, formulado por Machado, "ainda é somente uma tendência, vaga aspiração em busca de forma" ( $\mathrm{p}$. 157)..$^{5}$

Em 1950, Antonio Candido publica o artigo "Romance extensivo", versão inicial de um texto que viria a constituir parte do subcapítulo " $\mathrm{Um}$ instrumento de descoberta e interpretação" de Formação da literatura brasileira. $\mathrm{O}$ artigo vale por uma apresentação resumida das ideias de

maturidade social exigidas para o surgimento de um romance realizado, lembra o caso de Melville, que escrevia no meio provinciano dos Estados Unidos da década de 1850. Diante disso, Sérgio Buarque pergunta se a obra de Melville seria um romance de costumes, que era o gênero que Lúcia parecia ter em mente. E acrescenta: "pode-se considerar Moby Dick um romance, na acepção moderna e usual da palavra?" (HOLANDA, 1996, p. 267).

${ }_{5}^{5}$ Para a visão de Augusto Meyer sobre a irrupção da obra madura de Machado de Assis, ver MEYER, 1958. 
Antonio Candido sobre o desenvolvimento do romance brasileiro no período formativo, pois começa assinalando as limitações das obras iniciais do gênero, passa pela constatação da tendência do romance romântico para o levantamento da variedade regional do país e desemboca na sugestão de que o romance extensivo atuou como preparação para o surgimento da obra madura de Machado de Assis.

$\mathrm{Na}$ abertura do artigo, Candido indica que o romance brasileiro do período romântico poucas vezes alcançou realização artística de alto nível, sendo mais apreciável a sua atuação como "instrumento de interpretação social". Algo dessa função do romance também seria indicado por Lúcia Miguel Pereira a propósito de escritores como Macedo e seu esforço de interpretação do meio social em que viveram (cf. PEREIRA, 1957, p. 21). Nesse aspecto, Candido constata a importância do romance romântico brasileiro no tocante à investigação da variedade regional e humana, observando que, ao realizar a progressiva conquista literária da extensão territorial do país, com o levantamento e a incorporação da diversidade da vida social à imaginação literária, o romance promoveu uma tomada de consciência da realidade pelos letrados.

Mas a vocação extensiva do romance romântico também é vista por Antonio Candido como "documento da relativa rarefação de densidade humana; ligada quem sabe, à sedimentação relativamente pouco intensa da estrutura social" (CANDIDO, 1950, p. 6, grifo meu; cf. Idem, 1993b, p. 101). Como se vê, está em jogo, aqui, a questão básica da reflexão social suscitada pela crítica sobre o romance brasileiro em seus inícios, isto é, o sentimento de que a irrealização artística decorria de um déficit de desenvolvimento, e consequente complexidade, da própria vida social. Assim, para Candido, enquanto uma sociedade como a francesa permitia a Balzac a exploração em profundidade dos vasos comunicantes que ligam os diferentes grupos sociais, no Brasil riqueza e variedade tiveram de ser buscadas por meio do deslocamento no espaço.

A solução que Antonio Candido apresenta para a compreensão do problema da maturação do romance brasileiro - tendo em vista uma explicação plausível para o surgimento da obra de Machado de Assis será a caracterização de um processo coletivo e cumulativo da produção literária que ele expressa na metáfora da sedimentação do material estudado pelo romance extensivo, gerando uma "superposição progressiva de camadas que consolidava o terreno para a sondagem profunda de Machado de Assis" (CANDIDO, 1950, p. 6; cf. Idem, 1993b, p. 102).

Sem destoar muito, neste ponto, de outros críticos que o precederam, Candido parece tomar a própria matéria social brasileira como sendo insuficiente para a exploração romanesca das "complicações psicológicas", embora apresente a ideia então inovadora de um processo cumulativo que pôde se concretizar a despeito da suposta rarefação social. 
Complementando o argumento, Candido indica que o surgimento da burguesia (ou de um grupo social que poderia ser, até certo ponto, assimilado à burguesia) teria trazido "novos problemas de ajustamento da conduta", definindo "condições objetivas e subjetivas para o desenvolvimento da análise e o confronto do indivíduo com a sociedade" (CANDIDO, 1950, p. 5; cf. Idem, 1993b, p. 100).

Em outra passagem da Formação da literatura brasileira, Antonio Candido faz referência ao trabalho de Lúcia Miguel Pereira e comenta as "pesquisas psicológicas" de Machado de Assis, que consistem em "recusar o valor aparente do comportamento e das ideias", investigando a motivação profunda dos atos e pensamentos, de modo a apreender "certos abismos sobre os quais a engenharia da vida de relação constrói as suas pontes frágeis e questionáveis"; para ele, "uma literatura só pode ser considerada madura quando experimenta a vertigem de tais abismos" (1993b, p. 193). E argumenta que Machado de Assis, autor que mais explorou esse terreno, não teria sido uma figura isolada e sem predecessores, como predominantemente o considerou a crítica anterior, mas sim um "continuador genial", tendo sido em parte precedido por Alencar, cuja obra, "percorrida por frêmitos inesperados", não apenas desenvolveu a compreensão sociológica da vida urbana no romance, mas também iniciou a análise em profundidade da psicologia.

\section{Alencar, o Realismo e a superação machadiana}

Ainda em 1950, e antes de "Romance extensivo", Antonio Candido publicou um artigo sobre José de Alencar no Diário Carioca, que naquele ano passou por uma reforma ampla e inovadora para os padrões do jornalismo brasileiro. O texto apareceu em 28 de maio, data em que se inaugurou a seção "Letras e Artes", dirigida por Prudente de Moraes Neto, e foi estampado ao lado da coluna de Sérgio Buarque de Holanda, que então assumiu a crítica de livros do jornal, após longa colaboração no Diário de Notícias. O artigo de Candido, intitulado "Alencar e o dinheiro", correspondia a uma parte do capítulo "Os três Alencares" de Formação da literatura brasileira. Mais precisamente, correspondia à seção sobre o Alencar "dos adultos", que, ultrapassando o mito heroico e o amor idealizado, aprofundava, nos romances da cidade e da fazenda, os temas relacionados ao desnivelamento das posições sociais.

Tendo em vista a linha de desenvolvimento da ficção oitocentista, pode-se dizer que Antonio Candido valoriza, nessa parte da obra de Alencar, o esforço de atualização e desprovincianização do romance brasileiro. Com efeito, é ali que os grandes temas do romance românticorealista europeu, isto é, francês, são incorporados de maneira ampla e redimensionados para as circunstâncias locais. Comparado ao "realismo miúdo" de Joaquim Manuel de Macedo, que não ultrapassava as 
aparências banais nem a psicologia elementar, o romance urbano de Alencar introduzia em escala apreciável as questões modernas do realismo sério e problematizante. Se a obra de Macedo havia inaugurado no Brasil a trilha dos estudos de costumes urbanos, pautados na fidelidade ao meio social fluminense - tendo, nesse aspecto, conservado um valor documentário - , faltou ao autor de A moreninha a acuidade da análise social e psicológica, nele substituída por uma visão estreita, limitada a julgamentos sumários e convencionais. Sem ser apenas uma deficiência do autor, o confinamento provinciano da ressonância de sua obra decorria também, em parte, de sua aderência e conformação à mediocridade do meio social a que pertencia (cf. CANDIDO, 1993b, p. 121-9). Neste ponto, Candido parece concordar com a observação de Lúcia Miguel Pereira sobre as limitações do realismo brasileiro, considerando que, embora tenha cumprido uma função social relevante, o realismo dos românticos - no tocante à qualidade artística - "foi também fator de limitação, visto como a objetividade amarrou o escritor à representação de um meio pouco estimulante" (Idem, p. 104).

Em contraste, no romance urbano de Alencar, o elemento impulsionador do enredo envolve o drama do indivíduo que, confrontado com as exigências da sociedade burguesa, encontra-se dividido entre a necessidade de obter dinheiro e o desejo de preservar a disponibilidade para a vida do espírito: "O moço de talento, que nos seus livros parte sempre à busca do amor e da consideração social, tem pela frente o problema de ascender à esfera capitalista sem quebra da vocação" (CANDIDO, 1950, p. 5; cf. Idem, 1993b, p. 204). A escolha pelo dinheiro, na sociedade capitalista, continua Candido, leva à aplicação completa da vida a esse fim, implicando o abandono do sonho e da utopia, e provocando a "alienação da consciência", que se manifesta como "prostituição do sentimento e da inteligência" (CANDIDO, 1950, p. 5; cf. Idem, 1993b, p. 205).

Como se vê, a descrição desse ponto de partida basilar do enredo romântico-realista implica a referência inevitável ao romance francês e à experiência histórica nele formalizada. Em outro passo da Formação da literatura brasileira, Candido observa que a mola impulsionadora do romance romântico, o seu "nervo dialético", é "o conflito entre indivíduo e grupo, entre o gênio e os padrões sociais", que atua como traço "não apenas do Judeu Errante e do Conde de Monte Cristo, mas de Vautrin e Raskonikof" (CANDIDO, 1993b, p. 99). A apreensão do vínculo entre os grandes temas estruturadores do romance realista e a matéria social burguesa, no quadro do capitalismo em expansão, se mostra com clareza nos comentários de Antonio Candido sobre romancistas estrangeiros.

No texto já mencionado sobre Stendhal, Candido discute, em seus romances, a predominância do arrivismo, tema central do começo do século XIX, quando "as hierarquias sociais passam a se organizar mais 
segundo o critério do adquirido do que do herdado" (CANDIDO, 1992, p. 190), desde que se havia declarado a ascensão social franqueada ao talento; por isso, em Stendhal a luta pelo lugar social, que nele se organiza segundo o conflito entre o mérito e a hierarquia, tem força estruturadora. Seus romances são movidos pela "crença firme na elevação dos indivíduos pelo próprio esforço", e, integrados a essa nova experiência histórica, seus personagens centrais "têm sempre algo excepcional - seja devido à aplicação intensa da vontade, seja pelo vigor da paixão" (p. 193), partindo em busca da conquista de posição em uma sociedade ainda marcada pelos restos de privilégio imobilista.

De maneira ainda mais saliente, o esquema fundamental do conflito entre o indivíduo e a sociedade, no romance francês, é identificado e descrito com amplitude no estudo, parcialmente publicado em 1952, sobre O Conde de Monte Cristo, de Alexandre Dumas. Seu protagonista, Edmond Dantès - "arrivista como Rastignac e bonapartista como Julien Sorel" (CANDIDO, 1971, p. 13) -, é apresentado por Candido como um dos inúmeros personagens da literatura romântica europeia que dão a ver, em sua trajetória, "a nova fase de conquista da posição social pela seleção do talento e da habilidade" (p. 13). Moldado em parte sob influxo do modelo do herói byroniano, Dantès encarna o indivíduo solitário que se opõe radicalmente à sociedade, como personagem de exceção que procura sobrepor-se à norma social.

Sem retomar aqui os diversos aspectos da análise que Candido faz do romance de Dumas, lembremos que, a seu ver, a vingança pessoal, que move o enredo do romance, não apenas encarna o individualismo próprio da conduta burguesa no quadro da competição generalizada, como também possibilita "verificar a complexidade do homem e da sociedade, permitindo circular de alto a baixo na escala social" (p. 16). Segundo Candido, a sociedade implicada no romance romântico europeu "é diversificada ao extremo, estratificando-se com minúcia e comunicando de segmento a segmento", e o tema da vingança permite que o romancista investigue como se relacionam os diferentes grupos e âmbitos da sociedade, "ligando as camadas e desvendando conexões obscuras" (p. 167).

Trata-se de um "desnudamento da sociedade", que mostra "os fundamentos reais de uma situação social", articulando as diferentes camadas sociais: "o ombro-a-ombro motivado pela vingança nivela a alta sociedade ao bas-fond, revolvendo na sua marcha, como um arado espectral, as consciências e os níveis sociais" (p. 17). Ao fim, o percurso de Dantès deságua na desilusão; depois de bom moço, e injustamente condenado, ele se volta contra a sociedade e, realizada a vingança, Dantès constata a ilusão de tudo, e o preço de seu triunfo é pago com isolamento e desumanização (cf. Idem, p. 25). 
Assim, Antonio Candido descreve o esquema organizador do enredo romântico-realista como formalização literária da experiência histórica burguesa e assinala o impulso desmistificador do romance que desemboca na perda das ilusões. A configuração do realismo sério funciona como referência para aquilatar a atualização literária empreendida por Alencar, que, nas palavras do crítico, "sentiu [...] muito bem a dura opção do homem de sensibilidade no limiar da competição burguesa". A propósito do desnível do brasileiro em relação ao modelo europeu, o crítico observa que Alencar "não tinha, é certo, o senso stendhaliano e balzaquiano do drama da carreira, nem a ascensão, na sociedade em que vivia, demandava a luta áspera de um Rastignac ou um Julien Sorel". (CANDIDO, 1950a, p. 5; cf. Idem, 1993b, p. 205). Em outra passagem, Candido afirma que, mais do que a influência estrangeira, "funcionou aqui a fidelidade ao meio observado: e apesar da fascinação exercida por Balzac, Dumas, Feuilllet, nunca se traçou em nossa literatura um Rastignac, um Monte Cristo ou um Camors, incompatíveis com as condições ambientes" (1993b, p. 103-4).

Essas observações apontam a distância e a relação diferencial entre o romance brasileiro e seu modelo, mas, em Formação da literatura brasileira, a diferença parece ser compreendida sobretudo como uma diferença de grau, sem que a lógica própria da dinâmica social do país fosse captada em sua inteireza - embora já fosse pressentida no capítulo sobre Memórias de um sargento de milícias - assim como não se apreendia o deslocamento que essa lógica específica operava sobre os temas europeus. Nesse passo, sem dúvida interessava ao crítico mostrar como Alencar elevou o padrão do romance brasileiro, com o ganho em articulação com os temas atuais da sociedade moderna e o senso analítico com que ele ultrapassava a simples descrição dos costumes no estudo dos comportamentos - análise retomada e aprofundada, em seguida, na "marcha ascendente da pesquisa machadiana, de Ressurreição a Iaiá Garcia" (Idem, p. 266).

Tomando o desenvolvimento da ficção em prosa no conjunto, Antonio Candido apresenta as bases para uma compreensão renovada da posição de Machado de Assis, que deixava de ser visto como escritor desvinculado da tradição local. ${ }^{6}$ Para Candido, a aparente singularidade de Machado se explica, do ângulo da história literária, ao se identificar sua integração na linha que vem de Macedo, Manuel Antônio e Alencar, e, do ângulo crítico, ao se reconhecer sua capacidade artística de "fecund[ar] a fórmula do romance romântico, acrescentando à apresentação realista das relações sociais urbanas uma profundidade analítica, inaccessível à bonomia de Manuel Antônio, mas pressentida pelo Alencar de Senhora e Lucíola, no qual se entronca diretamente" (1993b, p. 104-5).

Além de definir, por meio da investigação histórica, o lugar da obra de Machado de Assis, Antonio Candido deixou registradas observações

\footnotetext{
${ }^{6}$ Como se sabe, as observações de Antonio Candido seriam desenvolvidas por Roberto Schwarz em seus estudos machadianos a partir dos anos 1970 (cf. SCHWARZ, 1977, 1990).
} 
sugestivas a propósito da postura do escritor diante das grandes ideias que mobilizaram a imaginação do século XIX. No artigo "Duas notas", de 1947, o crítico considera que "Machado é dos negadores mais completos que se conhece" e observa que, diferentemente de outros escritores da época, como Flaubert, Zola, Eça de Queirós e Aluísio Azevedo, que acreditavam na Beleza, na Justiça, na Ciência ou na Educação, "Machado sorri divertido ante esses palavrões que se escreviam com maiúsculas ao seu tempo", perseverando na "imparcialidade implacável" que o liga a escritores do século anterior e fundamenta sua visão do homem e da sociedade (CANDIDO, 2001-2002, p. 318-9). Embora atribuísse essa visão a um viés ahistórico, Candido não deixava de intuir o distanciamento de Machado em relação aos ideais modernos que balizavam a vida intelectual da época, pressentindo nele o questionamento de certa ideia de progresso que então se impunha.

Para terminar, digamos que Formação da literatura brasileira trazia uma contribuição inovadora para a interpretação da experiência histórica brasileira em seu contraste e tensionamento com a referência moderna (europeia), lançando as bases para uma crítica de maior alcance. Posteriormente, outro passo seria dado em "Dialética da malandragem", de 1970 (CANDIDO, 1993a), ensaio que, como explicou Roberto Schwarz, não apenas aprofundou o "esforço de interpretação da experiência brasileira", mas também inaugurou "a sondagem do mundo contemporâneo através de nossa literatura" (1987, p. 155). O estudo dos artigos de Antonio Candido dos anos 1940 e 1950, bem como do contexto de discussões em que se situam, possibilita discernir elementos que, retomados e desenvolvidos, abririam à crítica brasileira as possibilidades de uma contribuição efetiva para a reflexão estética e social, cuja ressonância ultrapassa em muito o enquadramento apenas nacional.

\section{Referências bibliográficas}

ARANTES, Paulo Eduardo. "Providências de um crítico literário na periferia do capitalismo". In: ARANTES, Otília B. F. e ARANTES, P. E. Sentido da formação: três estudos sobre Antonio Candido, Gilda de Mello e Souza e Lúcio Costa. Rio de Janeiro: Paz e Terra, 1997, p. 7-66.

ARANTES, Paulo Eduardo. Sentimento da dialética na experiência intelectual brasileira. Dialética e dualidade segundo Antonio Candido e Roberto Schwarz. Rio de Janeiro: Paz e Terra, 1992.

CANDIDO, Antonio. "Alencar e o dinheiro". Diário Carioca. Rio de Janeiro, 28 de maio de 1950a, p. 5-6.

CANDIDO, Antonio. "Batalhas". In: O albatroz e o chinês. Rio de Janeiro: Ouro sobre azul, 2010 ( $2^{\mathrm{a}}$ ed., ampliada), p. 71-9. 
CANDIDO, Antonio. "Da vingança". In: Tese e antítese. São Paulo: Companhia Editora Nacional, $1971^{\mathrm{a}}$ (2 $2^{\mathrm{a}}$ ed.), p. 1-28.

CANDIDO, Antonio. "Dialética da malandragem". In: O discurso e a cidade. São Paulo: Duas cidades, 1993a, p. 19-54.

CANDIDO, Antonio. "Duas notas". In: Literatura e Sociedade, n. 6. São Paulo, DTLLC-FFLCH-USP, 2001-2002, p. 317-20.

CANDIDO, Antonio. "Uma dimensão entre outras". In: Brigada ligeira e outros escritos. São Paulo: Ed. Unesp, 1992a, p. 187-96.

CANDIDO, Antonio. “Entre campo e cidade”. In: Tese e antítese. São Paulo: Companhia Editora Nacional, 1971b (2 ed.), p. 29-56.

CANDIDO, Antonio. “Esclarecendo”. Folha da Manhã. São Paulo: 9 de abril de $1944 a$, p. 7. (Republicado em Literatura e sociedade, n. 5, DTLLC-FFLCHUSP, 2000, p. 186-9).

CANDIDO, Antonio. "Ficção e confissão". In: Ficção e confissão: ensaios sobre Graciliano Ramos. São Paulo: Ed. 34, 1992b, p. 13-70.

CANDIDO, Antonio. Formação da literatura brasileira (momentos decisivos). Belo Horizonte: Itatiaia, $1993 b$ (7 $7^{\mathrm{a}}$ ed.), 2 v.

CANDIDO, Antonio. “Observações à margem”. Diário de S. Paulo. São Paulo, 12 de dezembro de 1946a, p. 4. (Republicado em O Jornal. Rio de Janeiro, 13 de abril de 1947, Revista, p. 2.)

CANDIDO, Antonio. "O romance e o D. Juan”. Folha da Manhã. São Paulo, 2 de abril de 1944b, p. 14.

CANDIDO, Antonio. "Romance extensivo". Diário Carioca. Rio de Janeiro, 2 de julho de 1950b, p. 5-6.

CANDIDO, Antonio. "Silone (I)". Diário de S. Paulo. São Paulo, 17 de janeiro de 1946b, p. 4. (Republicado em O Jornal. Rio de Janeiro, 20 de janeiro de 1946, $1^{\text {a }}$ seção, p. 6.)

DANTAS, Vinicius. Bibliografia de Antonio Candido. São Paulo: Duas cidades, 2002.

ESCOREL, Ana Luisa. “O retrato". In: De tudo um pouco. Rio de Janeiro: Ouro sobre azul, 2016, p. 13-4.

HOLANDA, Sérgio Buarque de. O espírito e a letra: estudos de crítica literária, v. II, 1948-1959. In: PRADO, Antonio Arnoni (org.). Idem. São Paulo: Companhia das letras, 1996.

MEYER, Augusto. "Alencar". In: A chave e a máscara. Rio de Janeiro: O Cruzeiro, 1964, p. 145-58.

MEYER, Augusto. “De Machadinho a Brás Cubas”. Revista do Livro, ano III, n. 11. Rio de Janeiro, setembro de 1958, p. 9-18.

MIRANDA, José Tavares de. "Antonio Candido viu o demônio aos cinco anos". Folha da Manhã. São Paulo, 19 de agosto de 1951, 3 caderno, p. 7.

MORAES NETO, Prudente de. "O romance brasileiro". In: MASSI, Augusto. Militante bissexto: o crítico Prudente de Moraes Neto. Tese de Doutorado. São Paulo: FFLCH-USP, 2004, p. 204-34. 
"NOTÍCIA de Antonio Candido". Diário Carioca. Rio de Janeiro, 26 de agosto de 1951, $2^{\mathrm{a}}$ seção, p. 2.

PEREIRA, Lúcia Miguel. Prosa de ficção (de 1870 a 1920). Rio de Janeiro: José Olympio, 1957 ( $2^{\mathrm{a}}$ ed.).

SCHWARZ, Roberto. Ao vencedor as batatas: forma literária e processo social nos inícios do romance brasileiro. São Paulo: Duas cidades, 1977.

SCHWARZ, Roberto. Um mestre na periferia do capitalismo: Machado de Assis. São Paulo: Duas cidades, 1990.

SCHWARZ, Roberto. "Pressupostos, salvo engano, de 'Dialética da malandragem'”. In: Que horas são? São Paulo: Companhia das letras, 1987, p. 129-55.

SCHWARZ, Roberto. "Os sete fôlegos de um livro". In: Sequências brasileiras. São Paulo: Companhia das letras, 1999, p. 46-58.

SERNA, Jorge Ruedas de la. "Antonio Candido: Cómo y por qué escribí Formação da literatura brasileira". Casa de las Américas, n. 268. La Habana, julio-septiembre 2012, p. 117-28.

Edu Teruki Otsuka é professor doutor do Departamento de Teoria Literária e Literatura Comparada da Faculdade de Filosofia, Letras e Ciências Humanas da Universidade de São Paulo. É autor de marcas da catástrofe: experiência urbana e indústria cultural em Rubem Fonseca, João Gilberto Noll e Chico Buarque (2001) e de Era no tempo do rei: atualidades das Memórias de um sargento de milícias (2016). Contato: eduotsuka@usp.br

ORCiD: https:// orcid.org/0000-0002-5283-6251 